\title{
ADDITIVE FUNCTIONS AND THEIR ACTIONS ON CERTAIN ELEMENTARY FUNCTIONS
}

\author{
ESZTER GSELMANN
}

Abstract. The main aim of this note is to provide sufficient conditions for an additive function to be a real derivation. Among others the following implication will be verified: Assume that $\xi: \mathbb{R} \rightarrow \mathbb{R}$ is a given differentiable function and for the additive function $d: \mathbb{R} \rightarrow \mathbb{R}$, the mapping

$$
x \longmapsto d(\xi(x))-\xi^{\prime}(x) d(x)
$$

is regular (e. g. measurable, continuous, locally bounded). Then $d$ is a sum of a derivation and a linear function.

Mathematics subject classification (2010): 39B82, 39B72.

Keywords and phrases: Derivation, linear function, elementary function.

\section{REFERENCES}

[1] Roman Badora, On approximate derivations, Math. Inequal. Appl., 9 (1): 167-173, 2006.

[2] ZOLTÁN Boros AND ESZTER GSELMANn, Hyers-Ulam stability of derivations and linear functions, Aequationes Math., 80 (1-2): 13-25, 2010.

[3] Eszter Gselmann, Derivations and linear functions along rational functions, Monatsh. Math., 169 (3-4): 355-370, 2013.

[4] Franz Halter-Koch And Ludwig Reich, Characterization of field homomorphisms by functional equations, Publ. Math. Debrecen, 56 (1-2): 179-183, 2000.

[5] Franz Halter-Koch And Ludwig Reich, Characterization of field homomorphisms by functional equations II, Aequationes Math., 62 (1-2): 184-191, 2001.

[6] Donald H. Hyers, On the stability of the linear functional equation, Proc. Nat. Acad. Sci. U.S.A., 27: 222-224,1941.

[7] Wolfgang B. Jurkat, On Cauchy's functional equation, Proc. Amer. Math. Soc., 16: 683-686, 1965.

[8] Palaniappan Kannappan and Svetozar Kurepa, Some relations between additive functions, I, Aequationes Math., 4: 163-175, 1970.

[9] MAREK KUCZMA, An introduction to the theory of functional equations and inequalities, Birkhäuser Verlag, Basel, second edition, 2009. Cauchy's equation and Jensen's inequality, edited by Attila Gilányi.

[10] Svetozar KurePa, The Cauchy functional equation and scalar product in vector spaces, Glasnik Mat.-Fiz. Astronom. Ser. II Društvo Mat. Fiz. Hrvatske, 19: 23-36, 1964.

[11] GyulaMaksa, On additive functions which differentiate elementary functions in some sense, Ann. Univ. Sci. Budapest. Sect. Comput., 41: 125-136, 2013.

[12] AKINORI NishiYAmA AND SôICHI HorinOuCHI, On a system of functional equations, Aequationes Math., 1: 1-5, 1968. 